ISSN 2338-5324 (print)

ISSN 2442-7276 (online)

Online di http://jkp.fkep.unpad.ac.id

DOI : $10.24198 / \mathrm{jkp}$

\title{
Spiritual Needs of Post-Stroke Patients in the Rehabilitation Phase
}

\author{
Sri Hartati Pratiwi, Eka Afrima Sari, Ristina Mirwanti \\ Faculty of Nursing, Universitas Padjadjaran \\ Email:Sri.Hartati.Pratiwi@Unpad.Ac.Id
}

Submitted: 24-8-2018 Accepted: 14-9-2018 Published: 25-12-2018

\begin{abstract}
Post-stroke patients experience in various disturbances including physical, psychological and spiritual aspect. Post-stroke patients in the rehabilitation phase focus more on physical needs while the unfulfilled spiritual needs can reduce the patient's health condition. Therefore, it takes action to meet the spiritual needs of patients. This study was conducted to identify the spiritual needs among post-stroke patients. The descriptive quantitative was used among post-stroke patients in Neurological Polyclinic and stroke center in one of the Hospital in Bandung in 2017. The sampling technique used was consecutive sampling with 83 samples included post-stroke patients who have full awareness and didnot experience of aphasia. The instrument of this study used Spiritual Needs Questionnaire (SpNQ) which consists of 4 dimensions including religious, peace, self-existence, and dimension of the giving needs. SpNQ had a validity coefficient of 0.73 and $\mathrm{r} 0.75$. Data were analyzed using frequency distribution. The results showed that the most of respondents feel the spiritual need in all dimensions. In the religious dimension, the majority of respondents desired to pray with others, to move closer to God and participate in various religious activities $(98.8 \%)$. In the dimension of peace showed the most of respondents desired to be more cherished by others $(96.4 \%)$. The most perceived item of respondents were forgiving someone from the past in the dimension of self-existence $(98.8 \%)$ and a solace for others in the dimension of the giving needs $(98.8 \%)$. The conclusion from this study was most respondents feel the spiritual needs in all dimensions. Based on these results, nurses are expected to provide advice to people around the patients to invite them in various religious activities. Nurses supposed more expressing affection to them and involving the patients in some family activities.
\end{abstract}

Keywords: Needs, rehabilitation, spiritual, stroke. 
Sri Hartati : Spiritual Needs of Post-Stroke Patients in the Rehabilitation Phase

\section{Introduction}

Stroke is one of disease that leading causes of death. The incidence of stroke in various countries has increased. The mortality of stroke in Asia was higher than in Europe or United States. Indonesia is one of the countries with high incidence of stroke in Asia (Kim, 2014). Based on the Basic Health Research (Riskesdas, 2013), the incidence of stroke in Indonesia has been increasing rapidly from 8.3 per 1000 residents in 2007 to 12.1 per 1000 population in 2013 (Ministry of Health, 2014).

Stroke is a disruption of blood flow to a part of the brain, which causes brain cells to be damaged or blockage in the blood vessels. Stroke can be caused by a rupture or a blockage of blood vessels in the brain. Hypertension, hypercholesterolemia, diabetes mellitus are the risk factor of stroke. These conditions can cause disruption of tissue perfusion so the brain has function disruption and even death. The impaired function of the brain can cause various disorders including physical disturbances, emotional disturbances and cognitive disturbances (Smeltzer \& Bare, 2010).

The post-stroke patients have experience in physical and emotional disturbances. The physical disturbances among stroke patients included the low function of extremity or even paralysis, swallowing disorders, speech impairment, visual impairment, and urinary or fecal incontinence (Smeltzer \& Bare, 2010). These physical disorders depend on the area that affected by perfusion disturbances and can cause disorder of daily activity (Dalvandi et al., 2010). The emotional disturbances among stroke patients was personality disorder, become irritable, anxiety, depression, emotional incontinence, and often felt run down (Kim, 2016). Most of patients with stroke have experience moderate anxiety (Pratiwi, 2017). In addition, poststroke patients often experience emotional expression disorders, catastrophic reactions, and fear of falling (Kneebone \& Lincoln, 2012).

Physical and psychological disturbances among stroke patients can lead to disruption of their functional activity which related to decline in quality of life. Most of patients with post-stroke have a low quality of life. This is due to the disruption of emotional status, physical weakness, and other demographic factors such as gender and level of education (Oros et al., 2016). In addition, depression and anxiety can affect the treatment outcomes among post-stroke patients (Clarke \& Currie, 2009).

The disturbances of physical, emotional, and cognitive among post-stroke patients resulted in them having to get comprehensive treatment in physical, psychological and spiritual care. The various therapies in the rehabilitation phase focus more on the interventions to coped with the various physical disorders than the psychosocial or spiritual disturbances. The previous studies showed some stroke patients consider that the spiritual dimension is very important to them (Owolabi, 2011).

Spiritual is linked to many important aspect of human functioning and can affect one's health condition. The individual's spiritual consist of three important elements includes of oneself, others and God. In addition, spirituality can be defined as the meaning and life expectancy and belief of a person so that it is viewed as a value and a belief (Dyson, Cobb, \& Forman, 1997). The compliance of spiritual needs among patients with chronic diseases such as stroke is very important. Patients still have the meaning and hope in living his life. It will relate to increase the quality of his life as well as the motivation to undertake the various therapies in the rehabilitation phase. This is in accordance with study conducted by Rowe and Allen (2004) that spirituality was the largest source of individual coping. Outpatient care is mostly done by families compared to health workers. The fulfillment of spiritual needs in outpatient services is often overlooked even though in this phase, patients have returned home and socialized with the community. The socialization can be disrupted by the limitations of post-stroke patients.

Nurses have a role in providing services holistically among post-strokepatients. Nurses are expected to assist patients in meeting their biological, psychological, social and spiritual needs. Nurses should be 
Sri Hartati : Spiritual Needs of Post-Stroke Patients in the Rehabilitation Phase

able to provide services with consideration to the body, mind and spirit holistically. The meet of the post-stroke patients needs has not only in physical and psychological needs but also in the spiritual need. Therefore, this study is important to examine the spiritual needs of post-stroke patients.

\section{Method}

This study used the descriptive cross sectional design to identify the spiritual needs of poststroke patients. This study was conducted among post-stroke patients at Neurological Polyclinic and Stroke Center in one of the Hospital in Bandung. The consecutive sampling method was used in this study. The inclusion criteria were more than 22 years old post-stroke patients, have full awareness and no communication problems, while the exclusion criteria was stroke patients who have unstable high blood pressure. 83 respondents,

Data collection techniques used questionnaire. The characteristic of respondents was assessed to see the homogeneity and other factors influencing the patient condition. The data was assessed consisting of age, gender, the education level, occupation, religion, income, marital status, length of stroke, type of stroke, comorbidities, and the history of stroke.

The spiritual needs of this study were measured using the Spiritual Needs Questionnaire (SpNQ), which was developed by Bussing, Balzat, and Heusser (2010). The time required in full filling this questionnaire was five minutes. The SpNQ consists of 19 items of questions under four dimensions: religious dimensions, inner peace, existential need (reflection/rerating), and actively giving. The scoring of this questionnaire was done by assessing the respondent's spiritual needs (yes/no), then assessing how important the needswas felt by the respondent with scale ranging from 1 (somewhat needed), (2) required, and (3) much needed. The SpNQ questionnaire has been used in Indonesian language with validity of 0.73 and $\mathrm{r} 0.75$ (Nuraeni et al., 2015). Descriptive analysis (frequency, percentage, mean, and median) were used to analyze and identify the spiritual needs of post-stroke patients by comparison of percentage of each needs.

\section{Result}

Table 1 The Respondents' Characteristics

\begin{tabular}{lcc}
\hline \multicolumn{1}{c}{ Characteristics } & Frequency & Percentage \\
\hline Age (years) & (f) & (\%) \\
$36-45$ & 3 & \\
$46-55$ & 42 & 3.6 \\
$>55$ & 38 & 50.6 \\
Marital Status & & 45.8 \\
Married & 75 & \\
Single & 0 & 90.4 \\
Widowed & 8 & 0 \\
Barthel Indeks & & 9.6 \\
Total Dependence & 2 & \\
Severe Dependence & 4 & 2.4 \\
Moderate Dependence & 4 & 4.8 \\
Mild Dependence & 18 & 4.8 \\
Independent & 55 & 21.7 \\
\hline
\end{tabular}


Sri Hartati : Spiritual Needs of Post-Stroke Patients in the Rehabilitation Phase

Table 2 Spiritual Needs of Post-Stroke Patients in Religious Dimension

\begin{tabular}{lclll}
\hline \multicolumn{1}{c}{ Spiritual Needs:Religion } & No & $\mathbf{( \% )}$ & Yes & $\mathbf{( \% )}$ \\
\hline Praying with others & 1 & 1.2 & 82 & 98.8 \\
Someone is praying for you & 3 & 3.6 & 80 & 96.4 \\
Praying alone & $\mathbf{2 0}$ & 24.1 & 63 & 75.9 \\
Turning to a higher presence (i.e., God, angels). & 1 & 1.2 & 82 & 98.8 \\
Participating in a religious ceremony & 1 & 1.2 & 82 & 98.8 \\
Reading spiritual/religious books & 5 & 6.02 & 78 & 93.98 \\
\hline
\end{tabular}

Table 3 Spiritual Needs of Post-Stroke Patients in Inner Peace Dimension

\begin{tabular}{lllll}
\hline \multicolumn{1}{c}{ Spiritual Needs: Inner Peace } & No & $\mathbf{( \% )}$ & Yes & $\mathbf{( \% )}$ \\
\hline Wish to dwell at places of quietness and peace & 7 & 8.4 & 76 & 91.6 \\
Finding inner peace & 7 & 8.4 & 76 & 91.6 \\
Talking with others about fears and worries & $\mathbf{3 2}$ & 38.5 & 51 & 61.5 \\
Plunge into the beauty of nature & 22 & 26.5 & 61 & 73.5 \\
More loving by others & 3 & 3.6 & 80 & 96.4 \\
Reading spiritual/religious books & 5 & 6.02 & 78 & 93.98 \\
\hline
\end{tabular}

Table 4 Spiritual Needs of Post-Stroke Patients in Existential Needs Dimension

\begin{tabular}{lllll}
\hline \multicolumn{1}{c}{ Spiritual Needs: Existential Needs } & No & $\mathbf{( \% )}$ & Yes & $\mathbf{( \% )}$ \\
\hline Reflecting on your previous life & 27 & 32.5 & 56 & 67.5 \\
Find meaning in illness and/or suffering & 20 & 24.1 & 63 & 75.9 \\
Talking with someone about the meaning of life/ & $\mathbf{2 2}$ & 26.5 & 61 & 73.5 \\
suffering & & & & 73.5 \\
Talking about the possibility of life after death & 22 & 26.5 & 61 & 98.8 \\
Forgiving and forgiven someone from the past & 1 & 1.2 & 82 & 93.98 \\
Reading spiritual/religious books & 5 & 6.02 & 78 &
\end{tabular}

Table 5 Spiritual Needs of Post-Stroke Patients in Actively Giving Dimension

\begin{tabular}{lllll}
\hline \multicolumn{1}{c}{ Spiritual Needs:Actively Giving } & No & $\mathbf{( \% )}$ & Yes & (\%) \\
\hline Turning to someone in a loving attitude & 4 & 4.8 & 79 & 95.2 \\
Giving away something for yourself & 3 & 3.6 & 80 & 96.4 \\
$\begin{array}{l}\text { Actively and autonomous intention to solace } \\
\text { someone }\end{array}$ & $\mathbf{1}$ & 1.2 & 82 & 98.8 \\
\hline
\end{tabular}

The characteristics of respondents in this study can be seen in Table 1. A total of 83 respondents showed the most of respondents were range of age of 46-55 years $(50.6 \%)$, Islam $(98.8 \%)$, married status $(90.4 \%)$, and independence $(66.3 \%)$.
Based on the results of this study, all items of spiritual needs were felt by the most of respondents. Only a small proportion of respondents were report that they did not need or had fulfilled the items of spiritual needs. The spiritual needs of post-stroke patients in the religious dimension can be 
Sri Hartati : Spiritual Needs of Post-Stroke Patients in the Rehabilitation Phase

seen in Table 2. As shown in Table 2, the item in religious dimension in spiritual needs revealed that the most needed $(98,8 \%)$ by the respondents were praying with others, turning to a higher presence, and participation in religious ceremonies. The spiritual needs in the dimension of inner peace can be seen in Table 3. The spiritual needs item in inner peace dimension showed that the most of respondent was more loving by others (96.4\%).

Table 4 shown spiritual needs in existential needs dimension. The most needed item by respondents was forgiving someone from the past $(98.8 \%)$. As shown in Table 5, the item in active giving dimension of spiritual needs which have the most needed by respondents was actively and autonomous intention to solace someone $(98.8 \%)$.

\section{Discussion}

The treatment of post-stroke patients should be holistic in terms of physiological, psychological, social and spiritual needs. The rehabilitation phase should not only focus in physical needs but also on social needs and spiritual needs. Stroke patients take less attention of spiritual needs whereas it's a need that greatly affects other needs including physical needs (Owolabi, 2011).

The spirituality can affect a person's health condition. Patients with chronic illness who have good spiritual wellbeing showed improve their health condition (Vilhena et al., 2014). A person who has a high spiritual level will experience in getting meaning of life (Visser, Garsen, and Vingerhoetsa, 2010). The spirituality can help a person by facilitating and improving emotional status, feelings of happiness, positive feelings and leading to a better life (Barlett et al., 2001). In addition, spirituality can help a person to be tougher in living his life (Owolabi, 2011). Spirituality can help patients struggle against chronic diseases by stabilizing the psychological and emotional conditions, finding hope and meaning of life and achieving peace despite suffering from chronic diseases (Bussing, Zhai, Peng, and Ling, 2013).

All the dimensions of spiritual need are required by the majority of respondents in this study. The patients with chronic diseases with various physical conditions and followed any treatments can cause various psychological disorders such as anxiety and depression. In such conditions, spiritual needs was one of the many needs needed by patients with chronic diseases as a coping mechanism in the face of all the stressors (Pulchalski, 2001; Rowe \& Allen, 2004). The spiritual needs consist of four dimensions including religious dimension, inner peace dimension, existential needs dimensionand actively giving dimension (Bussing, 2012).

In this study, the most of respondents have the most spiritual needs in religious dimension. This result was relevant with study conducted by Nuraeni et al. (2015) among cancer patients. The most needed items by the respondents were praying with others, turning to a higher presence, and participation in religious ceremonies. The majority of respondents in this study were late adult aged. They would begin to consider the meaning of life and more closer to the higher power of God. This finding is consistent with study conducted by Mc Cullough's research et al. (2005) that the higher of age will increase the religious condition as well. Most of the respondents in this study were independent so they can engage in various religious activities. Therefore, the majority of respondents in this study have selected item 'praying with others, turning to a higher presence, and participation in religious ceremonies'. Religion has a part in the rehabilitation phase among post-stroke patients includes the coping mechanism and acceptance of self-conditions, and therapist approach in rehabilitation therapy (Omu, AlObaidi, \& Reynolds, 2014). The resources of spirituality for patients in the most countries refer to the "religion" as the resources and coping.

All items in inner peace dimension of spiritual needs were required by the majority of respondents in this study. The most needed item wasmore loving by others. Patients with post stroke often have experience anxiety and depression so they need others to share (Pratiwi, 2017). The item 'talking with others about fears and worries' in inner peace dimension was the least needed by respondents in this study. This condition can be caused by the majority of respondents in 
Sri Hartati : Spiritual Needs of Post-Stroke Patients in the Rehabilitation Phase

this study have married and living with a partner so that items have been meet by the presence of their spouses. The perceived concerns of post-stroke patients are related to their health condition and physical limitations experienced by them. These conditions can lead feeling anxious and fear of their future (Kevitt et al., 2009).

The most needed item of existential needs dimension of spiritual need by respondents in this study was to forgiving someone from the past. Life in the past can affect a person's wellbeing. If the person has unresolved problems in the past so can lead to uncomfortable life. The items 'talking with someone about the meaning of life/suffering' and 'talking about the possibility of life after death' in the existential needs dimension showed the least needed by the respondents in this study. This could be happen due to majority of the respondents were Muslim which clearly illustrates that there is life after the death.

All the items in active giving dimension of spiritual needs were needed by respondents in this study. The most needed item by respondents was actively and autonomous intention to solace someone. In this dimension, a person has a need to give because by giving there wasa satisfaction and happiness. Despite the limited functionality in the activity, patients with stroke still want to have meaning of life of others so that they have needs for giving. This is in accordance with the meaning of spirituality for patients in Indonesia who has actively giving needs (Nuraeni, 2012). The chronic illness can bring a person to a better life. A small percentage of respondents in this study reported the needs item 'turning to someone in a loving attitude'. Research Limitation, none of the respondents in this study were included in the early adult range so they could not describe spiritual needs at various ages.

\section{Conclusion}

Based on the results of this study, the spiritual needs that respondent's requirement in sequence ranging from dimension of religious, inner peace, existential need, and actively giving. The religious dimension among poststroke patients in this study reported that the most needed was in religious dimension in spiritual needs revealed that the most needed was praying with others, turning to a higher presence, and participation in religious ceremonies. In the dimension of inner peace revealed that respondents in this study was to be more loved by others. The existential need dimension in this study revealed that the most needed was forgiving someone from the past. The active giving dimension of spiritual needs among post-stroke patients in this study was actively and autonomous intention to solace someone.

A nurse is a caregiver for patients and helps to meet their basic needs by providing nursing care.Nursing care in patients with chronic diseases especially in post-stroke patients should be done holistically both physiologically, psychologically, socially and spiritually. The treatment of post-stroke patients in the rehabilitation phase should not only focus on meeting physiological needs but also on psychological and spiritual needs. The meet of spiritual needs can affect to physiological and psychological well-being. In addition, the spiritual can be a coping mechanism among patients and provide experience in getting hope, and understanding the meaning of life so can achieve the tranquility.

The nursing care in meeting the spiritual needs of patients starts from the assessment of the condition and the spiritual needs of patients, providing the interventions appropriate to the patient's spiritual condition. Interventions of spiritual needs must be given in all dimensions including religious dimension, inner peace dimension, existential need dimension (reflection/rerating), and actively giving dimension. The religious dimension among post-stroke patients in this study reported that the most needed was in spiritual needs revealed that the most needed was praying with others. Most patients needed turning to a higher presence, and participation in religious ceremonies. In the dimension of inner peace revealed that respondents in this study was to be more loved by others. The existential need dimension in this study revealed that the most needed was forgiving someone from the past. The active giving dimension of spiritual needs among poststroke patients in this study was actively and 
Sri Hartati : Spiritual Needs of Post-Stroke Patients in the Rehabilitation Phase

autonomous intention to solace someone.

Based on the results of this study, nurses are expected to facilitate post-stroke patients in meeting the spiritual needs of religious dimensions by advising families to often invite patients to pray together, together come to various religious activities, and often watch religious events and provide books religious. In addition, nurses are expected to advise people around the patient to better express their affection to the patient, and allow them to engage in some family activities.

\section{References}

Barlett, S.J., Piedmont, R., Bilderback, A., Matsumoto, A.K., Bathon, J.M. (2001). Spirituality and well-being in persons with rheumatoid arthritis (Abstrak). Arthritis Rheumatoid, 44(Suppl 382).

Bussing, A., Zhai, X.F., Peng, W.B., Ling C.Q. (2013). Psychosocial and spiritual needs of patients with cronicdisease: Validation of the chinese version of the spiritual need questionnaire. J Integr Med., 11(2), 106-115. doi: 10.3736/jintegmed 2013020. Available at www.search.proquest.

Büssing, A., Balzat H.J., Heusser, P. (2010). Spiritual needs of patients with chronic pain diseases and cancer - Validation of the spiritual needs questionnaire. Eur J Med Res, 15, 266-273.

Büssing A, Janko A, Kopf A, Lux EA, Frick E.(2012). Zusammenhänge zwischen psychosozialen und spirituellen Bedürfnissen und Bewertung von Krankheit bei Patienten mit chronischen Erkrankungen. Spiritual Care, 1: 57-73

Clarke \& Currie. (2009). Depression, anxiety, and their relationship with chronic disease: A riview of the epidemiology, risk and treatment evidence. The Medical Journal of Australia, 190, 54 - 60. Available at www.mja.com.au.

Dalvandi, Heikkila, Maddah, Khankeh, \& Ekman. (2010). Life experiences after stroke among Irannian stroke survivors. International Nursing Review, 57(2), 247 - 253.doi: 10.1111/J.1466-7657.2009.00786.x. Available at onlinelibrary.wiley.com, retrieved December, 11, 2017.

Dyson, Cobb, \& Forman. (1997). The meaning of spirituality: A literature review. Journal of Advanced Nursing, 26, 1183 -1188. Available at www.researchgate.net, retrieved December, 11, 2017.

Kementerian Kesehatan Republik Indonesia. (2014). Info datin: Situasi kesehatan jantung. Jakarta: Pusat Data dan Informasi Kemenkes RI.

Kevitt, Fudge, Redfern, Sheldenkar, Chrichton, \& Wolfe. (2009). The stroke survivor needs survey. London: King's College London. Available at www.nao.org. uk.

Kim, J.S. (2014). Stroke in Asia: A global disaster. Int $J$ Stroke, 9(7), 856-7. doi : 10.1111/ijs.12317. Available at www.ncbi. nlm.nih.gov, retrieved December, 28, 2017.

Kim, J. (2016). Post-stroke mood and emotional. disturbances pharmacological therapy based on mechsnisms. Journal of Stroke, 18(3), 244-255. doi :http://dx.doi. org/10.5853/jos.2016.01144 Available at J-Stroke.org., retrieved December, 11, 2017.

Kneebone, L. (2012). Psychological problem after stroke and their management: State of knowledge. Neuroscience and Medicine, 3, 83-89. http://dx.doi.org/10.4236/ nm2012.31013. Available at file.scrip.org., retrieved December, 11, 2017.

Mc Cullough, Brion, Eenders, \& Jain. (2005). The varieties of religious development in adulthood: A longitudinal investigation of religion and rational choice. Journal of Personality and Social Psychology, 89(1), 78 -89 .

Nuraeni, A. (2012). Eksplorasi makna spiritualitas pada klien dengan sindrom coroner akut yang menjalani perawatan di Ruang Intensif Jantung RSUP Dr. Hasan Sadikin Bandung. Tesis, Universitas Padjadjaran, Bandung. 
Sri Hartati : Spiritual Needs of Post-Stroke Patients in the Rehabilitation Phase

Nuraeni, Nurhidayah, Hidayati, Sari, \& Mirwanti. (2015). Kebutuhan spiritual pada pasien kanker. Jurnal Keperawatan Padjadjaran, 3(2), 57 - 67.

Omu, O., Al- Obaidi, S. \& Reynolds, F. (2014). Religious faith and psichosocial adaptation among stroke patients in Kuwait: A mixed method study. Journal of Religion and Health, 53(2), $538-551$.

Oros, Popesco, Iova, \& Mihancea, I.C. (2016). Depression, activities of daily living and quality of life in elderly stroke patients. International Journal of The Bioflux Society, 8(1), 24-28. Available at www.hvm.bioflux. com.ro.

Owolabi, M. (2011). Impact of stroke on health-related quality of life in diverse cultures. The Berlin-Ibadan Multi Center International Study. Health and Quality of Life Outcomes, 9, 81.

Pratiwi, S.H., Sari, E.A. \& Hernawaty, T. (2017). Level of anxiety and depression in post-stroke patients at DR. Hasan Sadikin Hospital Bandung. Jurnal Pendidikan Keperawatan Indonesia, 3(2), 139-144.
Available at www.ejournal.upi.edu.

Pulchalski. (2001). The role of spirituality in health care. Baylor University Medical Center Proceedings, 14(4), 352 - 357.

Rowe and Allen. (2004). Spirituality as a means of coping with chronic illnes. American Journal of Health Studies, 19(1), 62-67. Available at www.search.proquest.co.

Smeltzer, S.O., \& Bare, B.G. (2010). Brunner \& Suddart Medical Surgical Nursing (12th Ed.). Philadelphia: Lippincott Williams and Wilkins.

Vilhena, Ribeiro, Silva, Pedro, Meneses, Cardoso, Silva, \& Mendonca. (2014). Psychosocial factors as predictors of quality of life in chronic portuguese patients. Health and Quality of Life Outcomes, 12, 3. Available at www.search.proquest.co.

Visser, A., Garssen, B., \& Vingerhoets, A. (2010). Spirituality and well-being in cancer patients: A review. Psycooncology, 19(6), $565-572$. 